J. Perinat. Med. 16 (1988) 405

\section{Fetal internal carotid artery flow velocity time waveforms in twin pregnancies}

\author{
Shimon Degani, Joav Paltiely, Reuven Lewinsky, Israel Shapiro, and Mordechai \\ Sharf
}

Ultrasound Unit, Department of Obstetrics \& Gynecology, Haifa Medical Center (Rothschild), Faculty of Medicine, Technion-Israel Institute of Technology, Haifa, Israel

\section{Introduction}

Twin pregnancies are frequently complicated by growth retardation in one or both fetuses [12]. Discordancy is difficult to recognize [17] and the risk of fetal mortality and morbidity is increased [8]. In twin pregnancies, two fetuses share the same uteroplacental circulation but usually have discrete umbilical placental circulations, representing a well controlled situation to relate fetal growth to Doppler studies of the umbilical placental circulation. GILES et al [10] studied umbilical artery flow velocity time waveforms in twin pregnancies as a measure of fetal placental blood flow resistance, and they found that an abnormally elevated A/B ratio (the ratio of peak systolic (A) to least diastolic (B) velocity) identified growth retardation. In this study the internal carotid artery waveforms of the two fetuses were recorded using the method described by WLADIMIROFF et al [19] and were related to fetal growth criteria by ultrasound and umbilical artery Doppler recordings.

\section{Material and methods}

Seventeen consecutive twin pregnancies were studied within 14 days of delivery. In all cases, clinical and early ultrasound dating were in agreement. The gestational age was confirmed after birth by DuBowITZ scores [7]. Ultrasonic measurements were made with a linear array real time ultrasound (Aloka SSD-256) equipped with a $3.5 \mathrm{MHz}$ transducer. A combined mechanical and pulsed Doppler system (Aloka SSD-730 and later Diasonics DRF 400 with carrier frequency of $3.5 \mathrm{MHz}$ ) was used for blood flow velocity measurements in the internal carotid artery and umbilical artery of each fetus. SGA was defined by fetal weight less than the 10th percentile, using the curves of BRENNER AND HENDERICs [3] for singleton pregnancies corrected for parity and sex. Average for gestational age (AGA) was defined by fetal weight between the 10th and 90th percentile. These criteria applied to our population. Ultrasound weight estimation was performed by the method developed by WARSOF [18] derived from measurements of biparietal diameter and abdominal circumference. A fetal weight estimation below the 10th percentile was considered to be abnormal.

Using the method described previously by WLADIMIROFF et al [19], the maximum flow velocity waveform in the internal carotid artery was obtained at the level of the bifurcation into the middle and anterior cerebral artery. The sample size of the Doppler probe was $4 \mathrm{~mm}$, allowing clear signals from the artery without interference from other nearby vessels. The maximum flow velocity waveforms in the umbilical artery were assessed by the method described by McCallum et al [16].

The degree of pulsatility of the waveform was quantified by calculating the pulsatility index, which is defined as the difference between peak systolic and end diastolic velocities divided by the averaged maximum flow velocity [11], calculated over at least four consecutive cardiac cycles. All the measurements were performed in the maternal semirecumbent position and during fetal apnea, since high amplitude fetal breathing modulates the blood flow velocity waveforms. 
Based on nomograms for normal singleton pregnancies [20] and a longitudinal study of 33 normal pregnancies of our population [4], pulsatility index cutoff values of 1.2 or less for the internal carotid artery, and 1.4 or more for the umbilical artery were considered abnormal. Statistical analysis was performed by using Student's t-test.

\section{Results}

The gestational ages at delivery ranged from 34 to 40 weeks, averaging 36.9. The mean period from study to delivery was 4.9 days, all subjects delivered within 14 days of study. All the twins were liveborn, without major congenital abnormalities. Three infants had a 5-min Apgar score of less than 7. There was no demonstrable twin-to-twin transfusion syndrome.

The mean ( \pm SD) birth weight was 2367 ( \pm 521 ). Actual birth weight discordancy of $20 \%$ or more was found in 4 of 17 twin pairs. In 9 pregnancies, one $(n=6)$ or both $(n=3)$ infants were small for gestational age (SGA). The mean ( \pm SD) birth weight of the 12 SGA newborns was 2120 ( \pm 379 ), whereas that of the 22 AGA newborns was 2502 $( \pm 546)$, a statistically significant difference $(\mathrm{p}<0.03)$. Doppler pulsatility index values of the two groups were significantly higher in umbilical arteries of the SGA group $(1.38 \pm 0.29$ compared to $1.07 \pm 0.17$ in the AGA group, $p<0.01$ ), and lower in the internal carotid arteries $(1.00 \pm 0.22$ compared to $1.43 \pm 0.17, \mathrm{p}<0.01$ ).
Comparative analysis of our results (table I) demonstrates the efficacy of the various ultrasound and Doppler parameters in predicting delivery of a SGA twin. The highest sensitivity $(83.3 \%)$, specificity $(95.5 \%)$, positive predictive value $(90.9 \%)$ and negative predictive value $(91.3 \%)$ was noted when using the pulsatility index of the internal carotid artery.

\section{Discussion}

Multiple gestations account for over $12 \%$ of all perinatal deaths [1], while comprising fewer than $1 \%$ of births. Fetal growth retardation affects one in four twins $[14,15]$. Intrauterine growth retardation in twins, where there has been differences of more than $25 \%$ between fetal weights, has been reported by BABSON et al $[1,2]$ to cause a long standing effect on the growth and intelligence of the smaller twin. In discordant twins the risk of fetal death has been reported to be increased 6.5 fold than normally grown twins [8].

Ultrasound is a useful tool in the assessment of growth problems, however the sensitivity of biparietal diameter differences of more than $7 \mathrm{~mm}$ in the same twin gestation in predicting growth failure has been reported at only $20 \%$ [16]. Fetal weight has been the primary parameter used in identifying infants with intrauterine growth retardation [5]. For these reasons estimating fetal weight from parameters determined by ultrasound has been the objective of many investigations.

Table I. Comparative analysis of twin assessment for pulsatility indices and ultrasound diagnosis of IUGR.

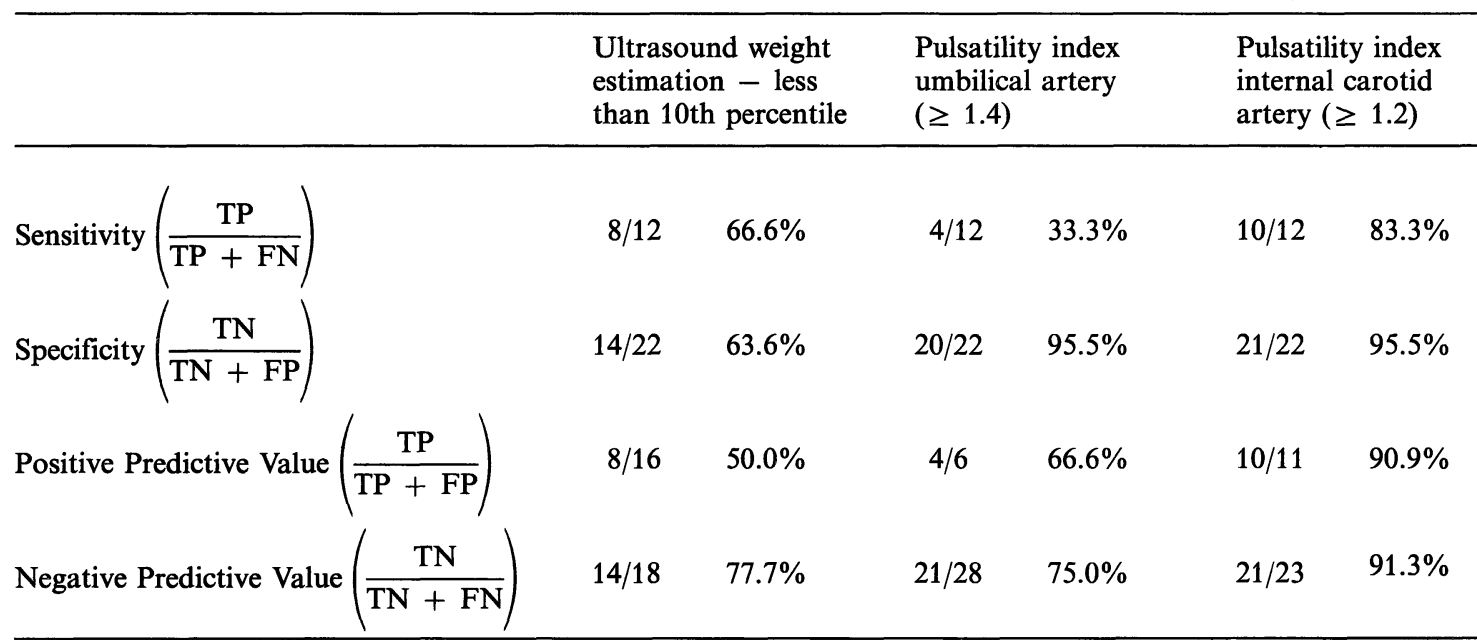


Currently the best method is that developed by WARSOF [18], mathematic fitting procedures were used to obtain a function relating the biparietal diameter and abdominal circumference to the birth weight. Estimates obtained using this function have been found to be relatively unbiased, to be more uniform over different weight classes and to have a random error of $\pm 8.8 \%$ (1 SD) [6].

In twin gestations, uteroplacental circulation is shared by the two fetuses and the differential growth pattern may be investigated by recording flow velocity-time waveforms from blood vessels of each fetus. GILEs et al [10] studied umbilical artery waveforms in twin pregnancies as an index of peripheral (or placental) resistance and found in those pregnancies, resulting in the delivery of a SGA infant, low diastolic flow velocities and high A/B ratios consistent with an increased fetal placental flow resistance. Comparative analysis of their results indicated that the $\mathrm{A} / \mathrm{B}$ ratios have a predictive value of $70 \%$ and a specificity of $70 \%$ in the diagnosis of the SGA twin. Umbilical artery velocity time waveforms allows the antenatal identification of a SGA twin in $70 \%$ of patients. These results compare favorably with those reported by Houlton [13] who used ultrasound diagnosis to find a $71 \%$ incidence of SGA among 28 twin paris with a BPD difference of $6 \mathrm{~mm}$ or more.

Vascular anastomoses in monochorionic placentas may affect the fetoplacental circulation. The clinical effect of such a link between twins ranges from undetectable to the classical twin to twin transfusion syndrome. ERSKINE et al [9] reported on a case of an arterial anastomosis detected antenatally using Doppler Technique. Umbilical ar- tery flow waveforms from the smaller fetus demonstrated a cyclical alteration of blood flow pattern during diastole ranging from absent through reverse to forward flow. Many types of anastomoses can occur between arteries and veins, as well as anastomoses within the capillary bed. The knowledge provided by the Doppler studies may explain IUGR and fetal death.

The umbilical artery Doppler assessment may present a problem in twin gestation as it is not always easy to clarify which fetus is associated with the umbilical vessel under study. Pulsatility index determination in the internal carotid artery provides direct evidence of the existence of the brain sparing effect in growth retarded fetus [19, 20]. Our findings suggest that decreased internal carotid artery pulsatility index is the best predictor of growth retarded twins.

In order to avoid too many flow velocity determinations, it may be more practical to use the ultrasound weight estimation below the 10 th percentile (sensitivity $67 \%$ ) or below the 25 th percentile (sensitivity $92 \%$ ) as a screening tool and then perform Doppler studies to determine the twin fetus at risk. Using these sequential tests (table II) the specificity is improved $(99 \% ; 98 \%)$ at the expense of reduced sensitivity $(56 \% ; 76 \%$ respectively).

The number of patients correctly classified using carotid flow waveforms in fetuses below the 10th percentile is $83.2 \%$ and $90.5 \%$ for fetuses below the 25 th percentile. Thus, we recommended the performance of Doppler studies in all twins below the 25 th percentile.

Table II. Comparative analysis of twin assessment by sequential testing - Ultrasound and Doppler.

\begin{tabular}{|c|c|c|c|c|}
\hline & $\begin{array}{l}\text { A } \\
=\text { Ultrasound } \\
\text { weight } \\
\text { estimation less } \\
\text { than } \\
\text { 10th percentile }\end{array}$ & $\begin{array}{l}\text { B } \\
=\text { Ultrasound } \\
\text { weight } \\
\text { estimation less } \\
\text { than } \\
\text { 25th percentile }\end{array}$ & $\begin{array}{l}\text { Sequential te- } \\
\text { sting } \\
\text { step 1: A } \\
\text { step 2: pulsatile } \\
\text { index - internal } \\
\text { carotid artery }\end{array}$ & $\begin{array}{l}\text { Sequential te- } \\
\text { sting } \\
\text { step 1: B } \\
\text { step 2: pulsatile } \\
\text { index - internal } \\
\text { carotid artery }\end{array}$ \\
\hline Sensitivity & $66.6 \%$ & $91.7 \%$ & $55.5 \%$ & $76.3 \%$ \\
\hline Specificity & $63.6 \%$ & $59.1 \%$ & $98.4 \%$ & $98.2 \%$ \\
\hline Positive Predictive Value & $50.0 \%$ & $55.0 \%$ & $94.9 \%$ & $95.8 \%$ \\
\hline Negative Predictive Value & $77.7 \%$ & $92.9 \%$ & $80.2 \%$ & $88.4 \%$ \\
\hline
\end{tabular}




\begin{abstract}
The fetal internal carotid artery and umbilical artery flow velocity time waveforms were studied in 17 consecutive twin pregnancies. The pulsatility index was calculated for each fetus in each artery as an index of vascular resistance. All studies were done within 14 days before delivery. In 8 pregnancies both fetuses were of birthweight appropriate for gestational age; whereas, in 9 patients one or both of the infants were small for ges-
\end{abstract}

tational age (SGA). From ultrasound criteria and Doppler studies of the umbilical and fetal internal carotid arteries, decreased fetal internal carotid artery pulsatility index (cut off value $\leq 1.2$ ) was found to be the best predictor of SGA (sensitivity $83 \%$, specificity $95 \%$, positive predictive value $91 \%$, negative predictive value $91 \%)$.

Keywords: Doppler, internal carotid artery, pulsatility index, twins.

\section{Zusammenfassung}

Flowmessungen in der fetalen Arteria carotis interna bei Zwillingsschwangerschaften

Bei 17 aufeinanderfolgenden Zwillingsschwangerschaften wurden Flowmessungen in der fetalen Arteria carotis interna sowie in der Umbilikalarterie vorgenommen. Für jeden Feten wurde in den beiden Arterien der Pulsatilitätsindex als Ausdruck des vaskulären Widerstands berechnet. Die Untersuchungen wurden 14 Tage vor der Entbindung vorgenommen. Bei 8 Schwangerschaften hatten beide Feten ein dem Gestationsalter entspre- chendes Gewicht, während in den 9 weiteren Fällen ein oder beide Feten untergewichtig waren (SGA).

Unter Berücksichtigung sonographischer Parameter und Doppleruntersuchungen der Umbilikalarterie sowie der fetalen Arteria carotis interna zeigte sich, daß ein erniedrigter Pulsatilitätsindex in der fetalen Arteria carotis interna (kritischer Wert $\leq 1.2$ ) ein SGA-Syndrom am besten voraussagt (Sensitivität $83 \%$, Spezifität $95 \%$, positiver prädikativer Wert $91 \%$, negativer prädikativer Wert $91 \%)$.

Schlüsselwörter: Arteria carotis interna, Doppleruntersuchungen, Pulsatilitätsindex, Zwillinge

\section{Résumé}

Vélocimétrie sanguine au niveau des carotides internes fatales au cours des grossesses gemellaires

Les grossesses gemellaires se compliquent fréquemment du retard de croissance de l'un ou des deux fœtus et le risque de mortalité et de morbidité est accru. Dans cette étude, on a étudié la vélocimétrie sanguine au niveau des carotides internes fœtales et des artères ombilicales au cours de 17 grossesses gémellaires consécutives; la vélocimétrie a été corrélée aux critères échographiques de croissance fotale. La vélocimétrie sanguine au niveau des carotides internes et des artères ombilicales a été étudiée selon les méthodes décrites par WLADIMIROFF et coll. [19] et par MC CALluM [16] respectivement. On a calculé l'index de pulsatilité pour chaque fœtus et pour chaque artère comme un index de résistance vasculaire. Pour 8 grossesses les deux fœtus étaient eutrophiques alors que pour les 9 autres l'un ou les deux fœtus étaient hypotrophes. Parmi les critères échographiques et les études doppler des artères ombilicales et des carotides internes, c'est la diminution de l'index de pulatilité de l'artère carotide interne (valeurs $\leq 1,2)$ qui assure la meilleure prédiction de l'hypotrophie (sensibilité $83 \%$, spécificité $95 \%$, valeur prédictive positive $91 \%$, valeur prédictive négative $91 \%$ ). Afin d'éviter de trop nombreux examens doppler, il peut être plus pratique de se servir de l'estimation pondérale échographique soit inférieure au 10ème percentile (sensibilité 67\%) soit inférieure au 25 ème percentile (sensibilité $92 \%$ ) comme outil de dépistage et seulement ensuite de réaliser l'examen doppler pour déterminer les foetus à risque. En se servant de ces examens successifs (tableau II) la spécificité est améliorée (99\% et $98 \%$ respectivement) au prix d'une diminution de la sensibilité $(56 \%$ et $76 \%$ respectivement). Le pourcentage de patients classés de façon correcte en se servant de l'étude vélocimétrique au niveau des carotides internes est de $83,2 \%$ chez les fœtus audessous du 10ème percentile et de $90,5 \%$ chez les fœtus au-dessous du 25 ème percentile. C'est pourquoi nous recommandons l'étude vélocimétrique chez tous les jumeaux au-dessous du 25 ème percentile.

Mots-clés: Artère carotide interne, Doppler, index de pulsatilité, jumeaux. 


\section{References}

[1] Babson SG, T Kangas, N Young, JL Bramhall: Growth and development of twins of dissimilar size at birth. Pediatrics 33 (1964) 327

[2] BABSON SG, DS PHILlips: Growth and development of twins dissimilar in size at birth. $\mathrm{N}$ Engl $\mathbf{J}$ Med 289 (1973) 937

[3] Brenner WE, DA Edelman, CH Henderick: A standard of fetal growth for the United States of America. Am J Obst Gynecol 126 (1976) 555

[4] Degani S, JaGW Van Den Wijngaard, JW WlaDIMIROFF: Assessment of cerebral blood flow by Doppler ultrasound. Harefuah 112 (1987) 427

[5] Deter RL, RB Harrist, FP Hadlock, RJ CarPENTER: The use of ultrasound in the detection of intrauterine growth retardation - a review. J Clin Ultrasound 10 (1982) 9

[6] Deter RL, FP Hadlock, RB HaRrist, RJ CARPENTER: Evaluation of three methods for obtaining fetal weight estimates using dynamic image ultrasound. J Clin Ultrasound 9 (1981) 421

[7] Dubowitz LMS, V Dubowitz, C Goldberg: Clinical assessment of gestational age in the newborn infant. J Pediatrics 77 (1970) 1

[8] Erkkola R, S Ala-Mello, O Pitroinen, P Kero, M SillanapaA: Growth discordancy in twin pregnancies: A risk factor not detected by measurement of biparietal diameter. Obstet Gynecol 66 (1985) 203

[9] ERSKine RLA, JWK RitchiE, GA MuRnaghaM: Antenatal diagnosis of placental anastomosis in a twin pregnancy using Doppler ultrasound. $\mathrm{Br} \mathbf{J}$ Obstet Gynaecol 93 (1986) 955

[10] Giles WB, BJ Trudinger, CM Cook: Fetal umbilical artery flow velocity time wave forms in twin pregnancies. Br J Obstet Gynaecol 93 (1986) 471

[11] Gosling RG, DH KING: Ultrasound Angiology. In: Arteries and Veins. (Marcus AW, L ADAMSON (eds): Churchill Livingstone, Edinburgh 1975
[12] HAWrylshyn PA, M BAKIN, A BernsteIn, FR RAPSIN: Twin pregnancies - a continuing perinatal challenge. Obstet Gynecol 59 (1982) 463

[13] HoultoN MCC: Divergent biparietal diameter growth rate in twin pregnancies. Obstet Gynecol 49 (1977) 542

[14] Leveno KJ, R Santos-Ramos, J Duenhoelter: Sonar cephalometry in twin pregnancy: discordancy of the biparietal diameter after 28 weeks' gestation. Am J Obstet Gynecol 138 (1980) 615

[15] Manlan G, K ScotT: Contribution of twin pregnancy to perinatal mortality and fetal growth retardation. Can Med Assoc J 118 (1978) 365

[16] McCallum WO, CS Williams, S Napel, RE DaIGLE: Fetal blood velocity waveforms. Am J Obstet Gynecol 132 (1978) 425

17] NeILSON JP: Detection of the small for dates twin by ultrasound. Br J Obstet Gynaecol 88 (1981) 27

[18] WARSOF ST: Ultrasonic estimation of fetal weight for the detection of intrauterine growth retardation by computer assisted analysis. Thesis, New Haven, Yale University School of Medicine, 1977.

[19] Wladimiroff JW, HM Tonge, PA Stewart: Doppler assessment of cerebral blood flow in human fetus. Br J Obstet Gynaecol 93 (1986) 471

[20] Wladimiroff JW, JAGW Van Den Wijngaard, S DEGANI, NJ NOORDAM, J VAN EYCK: Cerebral and umbilical arterial blood flow velocity waveform in normal and growth retarded pregnancies; a comparative study. Obstet Gynecol 69 (1987) 705

Received December 1, 1987. Accepted March 2, 1988.

Shimon Degani, M. D.

Dept. of Obstetrics \& Gynecology, Ultrasound Unit Haifa Medical Center (Rothschild)

P. O. B. 4940, Haifa 31048, Israel 